\title{
De Paracas a Nasca: \\ ¿POR QUÉ LA NECESIDAD DE ESTUDIAR UNA ÉPOCA «TRANSICIONAL»?
}

\author{
Ann H. Peters ${ }^{\mathrm{a}}$ \\ Elsa Tomasto-Cagigao ${ }^{\mathrm{b}}$
}

\section{Introducción}

Paracas apareció en la historia de los estudios arqueológicos luego de las excavaciones de Tello en sitios habitacionales y cementerios intrusivos localizados en la península de Paracas. Tello dividió la cultura material encontrada en estos sitios en dos fases, ambas definidas como Paracas: Cavernas, con sus tumbas en forma de botella, cerámica policroma con decoración de resinas aplicadas poscocción sobre espacios delineados con incisiones, textiles con decoración lineal e iconografía con rasgos similares a Chavín. Luego, Necrópolis, con sus entierros intrusivos de fardos funerarios en estructuras domésticas, cerámica monocroma, generalmente con engobe, textiles bordados con diseńos lineales y en bloques de colores, iconografía similar a la de Nasca (Paul 1991; Silverman y Proulx 2002; Tello 1929, 1959; Tello y Mejía Xesspe 1979). Si bien existen muchas diferencias en la cultura material atribuida a estas dos fases, el uso del término Paracas para ambas ha contribuido a la falsa impresión de una fuerte continuidad entre ellas, al punto de ser consideradas expresiones artísticas de sociedades que compartían una tradición cultural común (Menzel et al. 1964). Por otra parte, la cultura material de Nasca, la época subsiguiente, es lo suficientemente distinta como para que Nasca sea considerada como un desarrollo cultural diferente a Paracas. Y aunque existe consenso respecto a la fuerte relación entre Paracas y Nasca, todavía no se han encontrado todas las respuestas referentes a la naturaleza de dicha relación (Paul 1991). De esta manera, aunque los conceptos de "cultura Paracas» o «cultura Nasca» son cómodos para usarlos en los libros de difusión, no se debe permitir que impidan el análisis de la diversidad social y las complejas interacciones dentro y fuera de la costa sur-central. En este contexto, el estudio de la etapa que trascurre entre Paracas y Nasca, la que marcaría la «transformación» de la una hacia la otra, es crucial y ofrece innegables atractivos para la investigación del cambio y la continuidad en los procesos culturales.

La sociología ha desarrollado teoría y métodos de estudio de las transiciones sociopolíticas, con la ventaja de incorporar observaciones directas de la compleja dinámica entre un «régimen

\footnotetext{
a Consulting Scholar, American Section

University of Pennsylvania Museum of Archaeology and Anthropology

Correo electrónico: ann.h.peters@gmail.com

b Sección de Arqueología, Pontificia Universidad Católica del Perú

Correo electrónico: etomast@pucp.edu.pe
} 
sociotécnico» de prácticas de producción y formas de organización social establecidas —el locus (o loci) de innovación- y un contexto más amplio o "paisaje» que acondiciona la dinámica del cambio (Rip y Kemp 1988). En esta perspectiva multinivel para analizar los procesos de cambio y de sostenibilidad de un sistema tecnológico y social particular, el concepto de «paisaje» incluye no solamente rasgos geográficos y recursos naturales, sino también instituciones sociopolíticas, infraestructura de producción e intercambio, poblaciones y prácticas culturales que constituyen la realidad percibida. Una configuración sociotécnica dominante se compone de prácticas interrelacionadas o «rutinas», por ejemplo: sistemas de manejo de energía, agua y deshechos; formas de procurar, generar, intercambiar, almacenar, procesar y disponer de comestibles; técnicas de producir, valor de intercambio y significado social de los elementos de la cultura material; generación y renovación de relaciones de intercambio, que incluyen el parentesco, las alianzas, la competición y el enfrentamiento bélico; transmisión de información, que incluye conocimientos, sistemas de creencias, procesos de toma de decisiones y el sustento de las instituciones sociopolíticas involucradas. Todas estas prácticas y contextos organizacionales son interdependientes y se refuerzan mutuamente, ligados a un paradigma sociotécnico (Freeman 1992), y por lo mismo, resistente al cambio. Sin embargo, como el estrés se desarrolla tanto dentro de un sistema sociotécnico dominante, como en su relación con su paisaje, todo estudio de un proceso histórico es, en algún grado, un estudio de un sistema en transición.

Una breve discusión de los retos involucrados en aplicar esta literatura sobre procesos contemporáneos al análisis de datos arqueológicos debe señalar que estas propuestas deben mucho a la teoría marxista de una «formación social» constituida por la interacción entre recursos naturales, tecnologías de producción asociadas con una forma de organización social y relaciones de poder, que estructuran la apropiación de la labor y el flujo de bienes (Marx 1867; Althusser et al. 2016 [1965]). Cualquier formación social genera tensiones que resultan en procesos de cambio. En esta visión, una «transición a sostenibilidad» implica que las contradicciones entre el agotamiento o la renovación de recursos, la eficiencia y costo social de las prácticas productivas, y las políticas y prácticas generadas por líderes sociales, generan iniciativas de innovación. Estas innovaciones entran en conflicto con las prácticas dominantes, pero potencialmente pueden generar y sostener una formación social relativamente más estable. Cuando los arqueólogos notan tendencias hacia una mayor centralización sociopolítica o su colapso, con frecuencia ligándolas al incremento poblacional, a nuevas técnicas productivas, o al cambio ambiental, se indica un proceso de transición. Sin embargo, excepto cuando se nota evidencia de niveles de violencia interpersonal, los arqueólogos no suelen documentar evidencia de las tensiones específicas y de los contextos y formas de innovación que estructuran tales procesos. Las ontologías arqueológicas tienden a postular una sola causa a las transiciones sociopolíticas o sociotécnicas, y pocas veces exploran los mecanismos que pueden haber ligado la evidencia de un factor de estímulo potencial a un resultado histórico percibido. La literatura reciente sobre transiciones a sostenibilidad favorece modelos causales más complejos, que incorporan una discusión explícita de suposiciones fundamentales acerca de factores tales como, estructura social, cultura institucional, decisión racional o agencia estratégica. Geels (2010) recomienda que se contrasten varias miradas ontológicas distintas para el análisis de un proceso socioeconómico particular, para explorar su poder explicativo y sus implicaciones.

Un énfasis en contextos que facilitan o impiden la comunicación y la toma de decisiones, conecta el pragmatismo de este tipo de análisis, a la evidencia abundante de la importancia de las festividades, prácticas rituales y manifestaciones emblemáticas, tanto en contextos sociales actuales como en los del registro arqueológico. Un aspecto esencial de las transiciones sociotécnicas o sociopolíticas son los cambios en el sistema hegemónico de creencias (Gramsci 1932), o, a un nivel más general, en el marco cognitivo que informa y se refuerza en las prácticas de la vida diaria (Weber 1946; Braudel 1993). Una herramienta poderosa para el desarrollo de modelos de proceso y agencia en transiciones es el concepto de nicho, que se refiere a un contexto favorable a la innovación, 
generado por condiciones excepcionales que involucran recompensación y protección de riesgos. Aunque se caracteriza con frecuencia como un contexto de producción que sirve a una elite social, un locus de innovación o contexto de transición (Berkhout et al. 2003) también puede desarrollarse en el margen social o geográfico de un sistema socioeconómico dominante, un modelo aplicado a la transición Paracas-Nasca por Van Gijseghem (2006).

El concepto de transición, con su mandato de análisis complejo y detallado de los procesos, ofrece un marco útil para la interpretación de las evidencias de cambios en el registro arqueológico, que caracterizan el paso del Formativo Tardío hacia los Desarrollos Regionales caracterizados como Intermedio Temprano, en las cuencas que dan al Pacífico en la región suroeste de los Andes Centrales. La transición desde lo que denominamos tradición Paracas a los que llamamos tradición Nasca, se extiende durante varios siglos en diferentes valles de la Costa Sur de los Andes Centrales, e involucra múltiples estilos de artefactos, además de patrones distintos y cambiantes en la ubicación, arquitectura y organización de los sitios arqueológicos (Massey 1986; Schreiber y Lancho 2003; Isla 2009; Orefici 2012; Bachir Bacha y Llanos 2013; Peters 2013; Tantaleán 2016; Nigra 2017), que parecen indicar varios centros sociopolíticos cuyo desarrollo e influencia varían a través del tiempo.

En el camino a entender las sociedades que están detrás de la cultura material que denominamos Paracas y Nasca, el estudio de la cerámica ha sido y es crucial, por tratarse de un material tan sensible a la formación manual, la variación estilística y tan ampliamente conservado. De esta manera, los términos Paracas y Nasca se refieren también a tradiciones de producción alfarera asociadas a varias fases estilísticas (Fig. 1), con una relación compleja a secuencias ocupacionales (Rowe 1960; Menzel, Rowe y Dawson 1964; Proulx 1968; Wallace 1985; Massey 1986; García y Pinilla 1995; Isla y Reindel 2007; Peters 2013). Las tradiciones alfareras Paracas y Nasca han sido definidas a partir de cierto grupo de vasijas, aunque otras se han denominado Paracas o Nasca por haberse encontrado en los mismos contextos (una falacia según los principios del análisis arqueológico), o por usar los mismos engobes, aunque su forma y decoración fueran distintas. A pesar de ello, los conceptos de tradiciones alfareras Paracas y Nasca y los marcos histórico-temporales propuestos por Uhle (1914), Tello (1929, 1930), la conferencia Wenner-Gren (Bennett 1948) y la escuela de Berkeley (Rowe 1960; Menzel et al. 1964), han sido útiles para facilitar el análisis arqueológico en una época en que la medición de tiempo era el propósito central del análisis formal.

Hay un largo desarrollo de la cerámica que denominamos Paracas en estratos fechados aproximadamente entre los años 800 y 200 a.C. (Unkel y Kromer 2009), durante el Horizonte Temprano. Las características que definen la cerámica Nasca se consolidan en las fases cerámicas Nasca 2 y 3 y se extienden hasta Nasca 7, entre los años 80 y 650 d. C., durante el Período Intermedio Temprano (Isla y Reindel 2007, Unkel y Kromer 2009). Las fases Paracas 10 y Nasca 1 definen un período de transición, durante el cual las ocupaciones y los cementerios de la Costa Sur se caracterizan por la presencia de tres tradiciones de producción alfarera que han sido denominadas Paracas Tardío, Topará y Proto Nasca o Nasca Inicial, con evidencias de interacción y variabilidad regional entre ellas (Fig. 1).

Este amplio período transicional se inicia con la coexistencia de: 1) estilos incisos, modelados, con pintura poscocción o con decoración negativa, denominados Paracas 8 y 9 (Ica) o Pinta (PiscoChincha), y 2) estilos monocromos o bicromos, engobes aplicados precocción, con manejo del color en la cocción y eventual modelado o grabado, denominados Topará fase Jahuay, presente en los alrededores del valle de Cañete. Luego, los estilos agrupados como Pozuelo, Topará fases Jahuay 3 y Chongos, Paracas u Ocucaje 10 y Nasca 1 son ampliamente distribuidos entre Chincha y Nasca, pero con diferencias regionales, y un desarrollo temporal que ha sido generalizado como dos épocas: la del «Horizonte Temprano 10» (v.g. Ocucaje 10, Jahuay 3) y la del «Intermedio Temprano 1» (v.g. Chongos, Nasca 1). Las evidencias de interacción e innovación en esta época transicional aparecen en múltiples formas y en el desarrollo de engobes policromos, especialmente en los objetos asociados a los contextos mortuorios. Al final de este proceso, los estilos de Nasca 2 y 3, modelados 


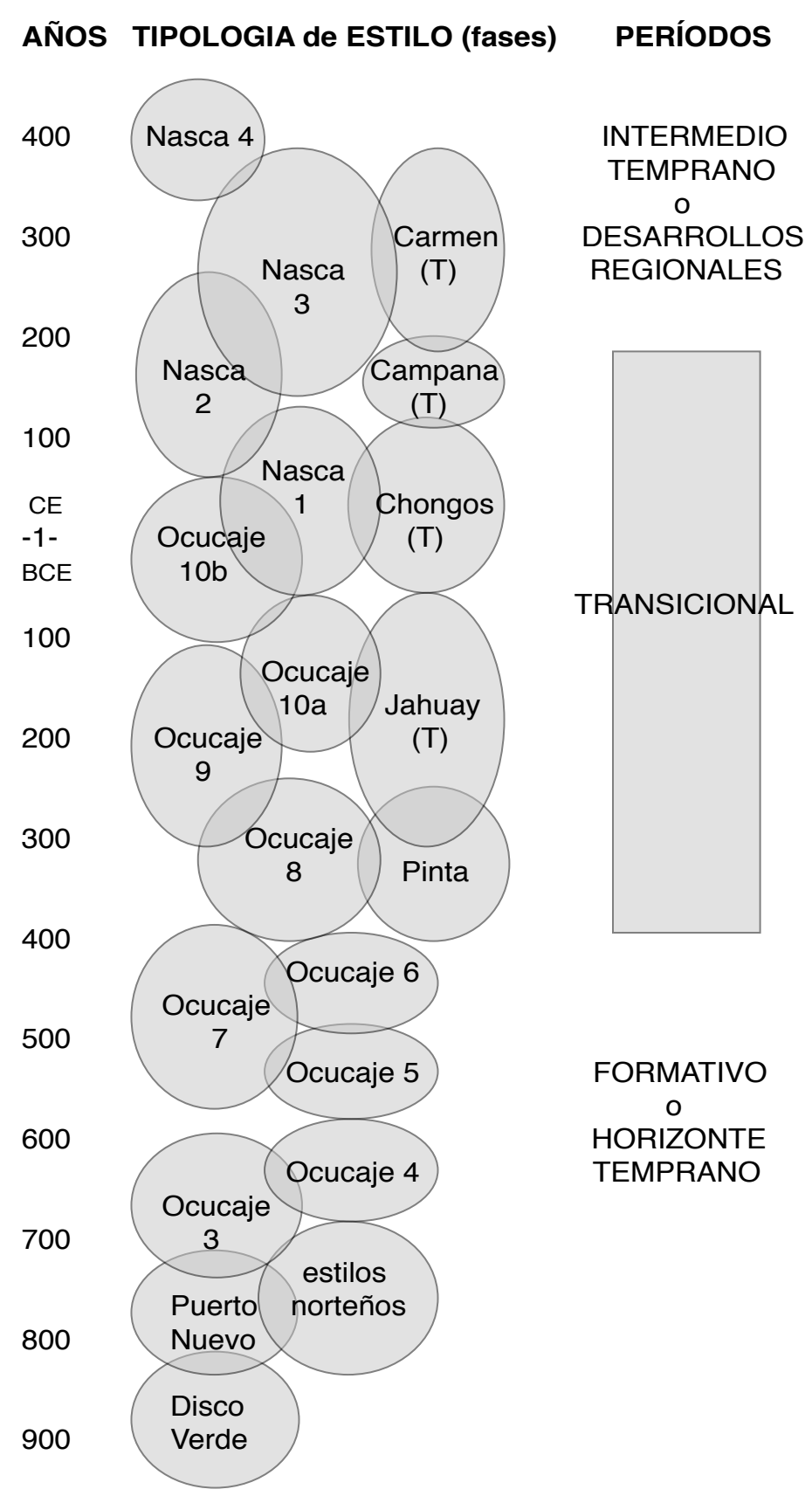

Cuadro cronológico de la transición Paracas-Nasca (A.H. Peters, 2018) 
y pintados con engobes policromos, dominan en la cuenca del río Grande de Nasca y el valle bajo de Ica, mientras que Topará fase Campana y ofrendas funerarias a escala reducida, aparecen en ocupaciones en el valle medio y alto de Ica, Paracas y más al Norte. La cerámica incisa y pintada que marcaba la tradición Paracas ha desaparecido y los engobes policromos se han generalizado, pero la dicotomía Nasca-Topará se reproduce luego en la amplia distribución de estilos denominados Nasca 2 y 3, mientras que ciertas prácticas de la tradición Topará se mantienen en el estilo Carmen, restringido mayormente a los valles de Chincha y Pisco.

Pero la arqueología no consiste en una historia de formas y estilos alfareros, sino en la historia de grupos sociales a través de todos los restos materiales que nos han dejado. Las similitudes formales en los restos materiales pueden relacionarse (aunque no siempre), con cercanía en identidad social, contacto social o contacto con los artefactos producidos por otra sociedad, y su utilidad para medir el tiempo deriva del habitus (Bourdieu 1977), de la moda (Barthes 1964) o de la imitación. Del mismo modo, la amplia difusión de una técnica, un estilo, un ícono o un tipo de artefacto indica una institución o red social (típicamente las dos) ligada a poderes sociopolíticos y prácticas compartidas por grupos diferentes, en el marco geográfico de su distribución (v.g. Vaughn y Van Gijseghem 2007), sin necesariamente borrar otras distinciones entre dichos grupos.

Para el caso que nos ocupa, el estudio de los complejos textiles y mortuorios ha sido de gran importancia, aun cuando no hay datos comparativos para toda la región. En general, se nota una interacción intensiva entre las poblaciones asociadas a las tradiciones Paracas y Topará en Ocucaje 10B, lo que se expresa de manera distinta en las tradiciones mortuorias Paracas Cavernas, Paracas Necrópolis y Ocucaje, aunque en estos mismos contextos aparecen artefactos mejor descritos como Proto Nasca, con técnicas e imágenes que no pueden ser explicados completamente por esa interacción. Luego, durante el período asociado a la diseminación de la cerámica Nasca fases 3 y 4 en toda la región, se da un cambio en los patrones mortuorios que parece indicar una diferencia en el rol social de los ritos mortuorios. Hay tumbas de fosa simple en el sitio de Paracas y en los valles de Pisco y Chincha, asociadas a cerámica Carmen (tradición Topará), pintada con engobes finos, que demuestran la influencia de la tradición Nasca y ya no se entierran fardos complejos y simples asociados a textiles de estilos diversos en el sitio de Paracas. En Cahuachi se documenta una dicotomía entre grandes tumbas de cámara formal asociados a ritos posteriores y tumbas de fosa simple (Orefici 2012).

En relación con el manejo del territorio, en toda la región se documentan patrones distintos y cambiantes en la ubicación, arquitectura y organización de los sitios arqueológicos (Massey 1986; Schreiber y Lancho 2003; Isla 2009; Orefici 2012; Bachir Bacha y Llanos 2013; Peters 2013; Tantaleán 2016; Nigra 2017). Estas transformaciones se perciben inicialmente en un crecimiento poblacional y el gradual abandono de asentamientos fortificados de Paracas Tardío, y también en cambios notables en la labor invertida en la construcción, mantenimiento y uso de espacios públicos, que se desplaza entre sitios ubicados en diferentes valles, o asociados a diferentes sistemas de manejo de agua y otras técnicas de producción, lo que sugiere cambios en las relaciones de poder.

Una serie de grandes complejos de plataformas y patios se asocian a Paracas 8, 9 y $10 \mathrm{~A}$ en el valle de Chincha (Canziani 2009; Tantaleán 2016, Tantaleán et al. 2017). En la misma época se construyen plataformas con patios en los sitios de Chongos en el valle de Pisco (Peters 2013), el sitio de Ánimas en la cuenca de Callango, valle bajo de Ica (Massey 1991; DeLeonardis 1997; Bachir Bacha y Llanos 2013; Bachir Bacha 2017), y el sitio de Cahuachi en el valle de Nasca (Strong 1957; Orefici 1998; Bachir Bacha 2007). Otras ocupaciones contemporáneas suelen agruparse en los márgenes de los valles, especialmente en laderas empinadas cerca de puntos estratégicos para el manejo de agua o playas protegidas, ricas en recursos marinos. En las alturas de la cuenca de Palpa, se identifican sitios contemporáneos donde se accedía a recursos altoandinos (Reindel 2014; Reindel e Isla 2017). Luego, las innovaciones de Paracas 10B, las fases Chongos, Campana (tradición Topará) y las fases Nasca 1/2/ 3 (inicial), están asociadas a la reubicación de ciertos 
centros principales de actividades públicas, lo que indica un cambio en el dominio sociopolítico. Las actividades de construcción disminuyeron en el valle de Chincha, mientras que en el valle de Pisco el sitio Alto del Molino (también conocido como Pachinga) dominó a Chongos (Peters 1997) y en Ica la cuenca de Ocucaje dominó a Callango (Menzel et al. 1964). En cambio, el sitio de Paracas continúa como centro de ritos mortuorios importantes a nivel regional (Tello y Mejía 1979; Tello 2009, 2012) y la construcción y el uso de plataformas monumentales continúan en Cahuachi (Orefici 2012). Más adelante, con la hegemonía de los estilos Nasca 2 y 3, Cahuachi pasa de ser un centro público entre otros, a un centro masivo cuya influencia se siente en toda la región. La cerámica Carmen aparece junto a cambios en las prácticas de construcción, análogas — pero no idénticas- a las documentadas en Cahuachi. Muchos de los edificios de adobes y cantos rodados asociados a Carmen se encuentran sobrepuestos a estructuras y ocupaciones de la tradición Topará (Peters 1997; Silverman 1997; Pérez et al. 2015). Pero en los sectores altos, al Este de cada valle costero, las ocupaciones asociadas a Carmen se ubican más cerca al punto donde cada río emerge en la cordillera andina, lo que sugiere un cambio en las estrategias de manejo del agua (Peters 2013).

Los estilos de artefactos y los contextos de su depósito final indican cambios en la organización social de la producción y en los patrones de intercambio y distribución de bienes emblemáticos y apreciados. Se documentan el abandono del culto religioso relacionado con el denominado Ser Oculado, el aumento en la frecuencia de la práctica de elaboración de las cabezas trofeo, y el trazo de geoglifos en las laderas de los cerros desérticos en toda la región que también constituye una práctica del período transicional, indicada por íconos y estilos emblemáticos de Paracas 8,9 y 10, y Nasca 1 (Isla y Reindel 2007; García 2013), que anteceden los trazos geométricos en las planicies de las pampas y terrazas desérticas.

Con rasgos de una transición con aspectos políticos, este proceso definido solamente a base de restos arqueológicos también demuestra elementos de una transición sociotecnológica. Por ejemplo, la organización de la producción de artefactos emblemáticos cambia profundamente, especialmente para la cerámica más elaborada y los textiles que llevan imágenes ligadas al discurso mítico y la ideología hegemónicos, y posiblemente también, a los centros sociopolíticos y sus líderes. Mientras los textiles y la cerámica que no llevan imágenes complejas se producen en varias formas relativamente consistentes, en los contextos definidos como Paracas Tardío (Cavernas, Ocucaje 8, 9 10), Topará (Paracas Necrópolis, Jahuay, Chongos, Campana, Carmen) y Nasca temprano (fases 1, 2 y el inicio de 3), los artefactos que llevan imágenes complejas tienden a variar siempre a nivel de su color, su diseño, y elementos de la iconografía. En contraste, mucha cerámica clasificada como Nasca 3 y 4 , y los textiles asociados, parecen haberse producido en lotes con un alto nivel de similitud en sus materiales y su estilo, lo que indica mayor centralización en la producción en ambas clases de soporte material. En el caso de la cerámica elaborada con características consistentes, se ha documentado una amplia diseminación en contextos habitacionales, en asentamientos ubicados en toda la región, y Vaughn y Van Gijseghem (2007) proponen un modelo de producción basado en Cahuachi. Aquí se argumenta, que este cambio global en los patrones de variabilidad, tanto en la cerámica como en los textiles más elaborados, marca un cambio en el paradigma sociotécnico que puede extenderse a otros tipos de actividades productivas y aspectos de la vida social.

Por todo esto, el período «transicional» merece y requiere de un estudio propio, porque nunca se va a poder entender la dinámica de interacciones y cambios que lo caracterizan, si siempre se figura como el inicio o el final de otro período histórico. La terminología establecida expresa continuidad en la dicotomía Paracas Cavernas/Necrópolis y ruptura histórica y cultural entre Paracas y Nasca. Esto ha creado una barrera en el análisis de las características y los procesos de transformación aquí mencionados, que distinguen al período asociado a ocupaciones contemporáneas a Paracas 8 a 10 y Nasca 1 a 3. En esta propuesta de estudio de la «transición Paracas-Nasca» enfatizamos un interés compartido en desarrollar modelos de prácticas productivas, de rituales significativos y de interacciones políticas entre diversos grupos sociales centrados en la actual región de Ica, entre c. 250 a.C. 
y 250 d.C., así como en los evidentes procesos de innovación y transformación que caracterizan este período. Se debe utilizar los conceptos establecidos de "fases», «horizontes», "períodos» o "culturas» con gran cautela, cuidando de que no obstaculicen subsecuentes avances en el estudio de procesos sociales a través de los restos materiales. Aquí se trata de superar fronteras conceptuales para hablar de las transformaciones de carácter cultural, social y político asociadas a lo que denominamos Paracas Tardío, Topará y Nasca Temprano en la vertiente occidental de la cordillera andina, entre Chincha y Nasca.

Con el propósito de iniciar la discusión sobre este período tan importante y que al mismo tiempo se ha venido estudiando de modo relativamente tangencial, se presenta este volumen que reúne investigaciones presentadas en el simposio Paracas - Nasca: Una época "transicional» del Formativo Tardio, Costa Sur de los Andes Centrales, llevado a cabo en agosto de 2012 en Ica. El término "transición» fue utilizado en un principio como título de la conferencia de 2012 para enfatizar que el tópico no se define por fases particulares, estilos de cerámica, o un grupo de sitios ya descritos en la literatura arqueológica, sino que busca generar nuevos acercamientos a un proceso histórico dinámico, basados tanto en las documentaciones previas, como en nuevos análisis de evidencia arqueológica.

Las colecciones de Tello son cruciales para el estudio del período transicional, no solo porque se encuentran en el origen de esta discusión, sino porque la península de Paracas fue al mismo tiempo una frontera geográfica y cultural para las tres tradiciones en interacción. En este sentido, Makowski y Kolomanski, hacen una excelente revisión de los estudios concernientes al Horizonte Temprano en la Costa Sur y de los fundamentos teóricos que están detrás de las definiciones de Paracas. En opinión de los autores, la presencia de varios estilos en interacción caracteriza a toda la secuencia Paracas, y para demostrarlo analizan una muestra de 67 vasijas procedentes de las excavaciones de Tello en Cerro Colorado, tanto de entierros en cavernas como de entierros en fosas. Luego de un minucioso análisis morfológico y de acabados de superficie, los autores concluyen que el corpus cerámico Paracas Cavernas de Cerro Colorado, incluye ejemplares de varios estilos contemporáneos, similares a vasijas Jahuay-Topará y Ocucaje, lo que indicaría su variada procedencia y la ausencia de una tradición alfarera originaria de la bahía de Paracas.

De manera similar, Tinteroff presenta un estudio detallado y sistemático de la cerámica de Wari Kayán. Parte de un modelo que propone que la transición Paracas-Nasca corresponde a la emergencia de una organización sociopolítica multicultural, caracterizada por la diversificación cultural de las poblaciones Paracas en tres comunidades: Paracas, Topará y Nasca, cada una de ellas asentada en uno o algunos valles de la Costa Sur, y manteniendo redes de intercambio social, político y económico. Al encontrarse fuera de los valles donde se asientan los poderes, el cementerio de Wari Kayán jugaría un papel fundamental en la cohesión regional, al tratarse de un lugar neutral y sagrado donde se entierran las elites de las diferentes comunidades. A través del cruce de información de publicaciones, archivos e inventarios, Tinteroff identifica un corpus de aproximadamente 554 piezas cerámicas excavadas por Tello en Wari Kayán, la mayor parte del cual permanece sin estudiar en el MNAAHP y del cual ha sido publicado solo aproximadamente un 2\%. De este corpus, Tinteroff ha logrado analizar 115 piezas, y presenta en este volumen los resultados del análisis tecnológico-morfológico (de formas y acabados de superficie) de 44 piezas, cuyo contexto pudo ser establecido. De esta manera identifica cuatro grupos tecnológico-morfológicos, algunos de los cuales corresponderían a ofrendas de grupos locales de nivel social bajo, mientras que otros serían ofrendas de grupos de niveles medio y alto procedentes de toda la región.

En la misma línea, Peters hace una evaluación exhaustiva de 16 fardos procedentes de las Necrópolis de Wari Kayán y los compara con otros 60 procedentes de Wari Kayán y de Arena Blanca. Basada en una meticulosa tipología de artefactos textiles y no textiles, Peters analiza su distribución en cada fardo y encuentra que existen contextos de tradición «más Paracas», que contienen artefactos, formas de prendas y decoración parecidos a los encontrados en Paracas 
Cavernas y Ocucaje 10, y que comparten prácticas en la preparación del cuerpo y la creación del fardo. Este conjunto de rasgos (artefactos, prendas, decoración y prácticas) son distintos a los encontrados en fardos que contienen artefactos de estilo "más Nasca». Asimismo, encuentra que la variación formal de los artefactos responde no solo al factor tiempo, sino a diferencias entre los grupos de productores que crearon los objetos. De esta manera, los tipos y estilos más frecuentes en cada contexto representarían aspectos centrales de la identidad sociocultural del individuo y de las personas a cargo de los rituales funerarios, mientras que los elementos de tipo o estilo minoritario, representarían a una red de interacción social más amplia. Es así que los fardos más grandes, que contienen más objetos y de mayor variedad corresponderían a personajes o a grupos de parentesco encargados de los rituales postmortem con acceso a un círculo social más amplio, en un modelo de intercambio en el cual el liderazgo social se fundamentaría en el desarrollo de relaciones diversas. Se plantea entonces que los fardos más grandes corresponderían a líderes sociales que habrían contribuido a la interacción entre grupos ligados a las tradiciones Paracas Tardío, Topará y Nasca y a la transformación política y cultural en esta época. En este contexto, el rito mortuorio y ancestral que creó el cementerio de Wari Kayán habría jugado un papel central en la transición Paracas-Nasca, notándose los cambios de poder sociopolítico en la transformación de los artefactos y las distintas formas de distribuirlos en los fardos a través del tiempo.

Por su parte, Velarde y Castro de la Mata presentan los resultados de su estudio de los objetos de metal hallados en los fardos de Wari Kayan. Basadas en una comparación tecnológica y estilística de los metales Ocucaje, Nasca y Wari Kayan, demuestran que, aunque los cambios tecnológicos no son importantes, sí existen cambios estilísticos muy notorios a lo largo del uso del cementerio de Wari Kayán, los cuales tienden hacia una mayor variabilidad tipológica y una simplificación en la factura y el acabado, así como la introducción de nuevas formas que se harán más frecuentes en Nasca

De esta manera, cinco investigadores, analizando distintos grupos de artefactos de las colecciones de Tello de la Península de Paracas, llegan a conclusiones similares: que en estas colecciones, más que una unidad cultural o dos fases, como lo había planteado Tello, existe una amplia variedad de artefactos y evidencias de una intensa interacción regional a lo largo del tiempo, la cual al mismo tiempo es producto de y contribuye a las transformaciones políticas, económicas y sociales que llevan desde Paracas hasta Nasca.

Respecto a lo que ocurre hacia el sur de esta zona de intensa interacción, Cadwallader et al. presentan los resultados de la prospección de un asentamiento de la época de transición, el sitio 1004, localizado en la cuenca de Samaca, en la parte baja del valle de Ica, el cual además se ubica cerca de geoglifos similares a los de las pampas de Nasca. En este artículo, y a pesar de las limitaciones que impone el estudio de un sitio sin excavaciones, Cadwallager y colegas se apartan de los estudios mortuorios y en centros administrativos y nos presentan evidencias de lo que sería la vida cotidiana en este período. A partir del estudio de la cultura material del sitio, que incluye cerámica, textiles, redes, material lítico, restos botánicos y de fauna y restos humanos, los autores nos presentan a una población con estrategias de subsistencia variadas, evidenciando un manejo eficiente del medioambiente. Así mismo, encuentran rasgos que sugieren un posible ambiente social convulsionado. Los autores consideran que el sitio 1004 es similar a otros de la época y por tanto, sus habitantes participaron de los acontecimientos que marcaron la época de transición.

Por su parte, Isla y Reindel presentan resultados de sus estudios sobre esta época en los valles de Palpa, incluyendo aspectos del patrón de asentamiento, prácticas funerarias, petroglifos, geoglifos y cerámica. Comparando estos elementos con los rasgos típicos de Paracas y de Nasca, Isla y Reindel encuentran que, más que una continuidad entre ambas, lo que se percibe en los valles de Palpa son cambios fuertes y abruptos. Estos cambios se refieren tanto al tamaño de la población, como al uso del territorio, la aplicación de nuevas tecnologías cerámicas que va acompañada de la aparición de nuevas formas de vasijas, un aumento en la producción de petroglifos y geoglifos en relación con 
los tiempos precedentes, y en el caso de los geoglifos, el uso de una técnica distinta a la que posteriormente usarían los Nasca. Isla y Reindel interpretan estos cambios en relación con la irrupción de elementos de la cultura Topará en los valles de Palpa, la cual tendría un rol decisivo en el aumento de la complejidad social y el desarrollo de la subsiguiente cultura Nasca.

Los mismos autores presentan además nuevas evidencias halladas en la sierra adyacente a los valles de Palpa, zona donde se originan los ríos que forman dichos valles. Sus estudios en esta región les permiten afirmar que en ella hubo una ocupación continua de todos los períodos prehispánicos y particularmente de Paracas, Nasca y del tiempo de transición entre las mismas, y que, tal como ocurre hoy en día, ambas regiones estuvieron integradas por un mismo proceso cultural, activo y dinámico a través del tiempo. En este contexto, durante la época de transición los autores advierten que la influencia Topará también llegó a la sierra de Palpa, y está relacionada con una migración fuerte de los pobladores de la sierra hacia zonas más bajas de los valles. Así mismo, encuentran evidencias de que los habitantes de la sierra estuvieron dedicados a la producción de bienes agrícolas, así como al acopio y transformación de recursos como la obsidiana y la fibra de camélido, tan importante esta última en la producción de los textiles que fueron centrales en los procesos de interacción y negociación entre las elites, que marcaron el paso entre una etapa y otra.

Y en relación con las innovaciones tecnológicas que marcan esta época, Van Gijseghem y colegas presentan sus investigaciones en la Mina Primavera, lugar donde existen evidencias de explotación de hematites desde la época de transición entre Paracas y Nasca. Este mineral está relacionado con la implementación de la pintura precocción en la cerámica, que marca el final de Paracas. Con un minucioso análisis de las áreas de actividad dentro de la mina, los objetos asociados y 17 fechados radiocarbónicos, demuestran el aumento gradual de la explotación minera desde Paracas Tardío hasta Nasca Temprano y plantean que tanto el material extraído como la actividad minera en sí estarían cargados de un fuerte componente simbólico. De esta manera abordan no solamente aspectos tecnológicos sino también rituales y ceremoniales relacionados con la transición

Con estos cuatro artículos tenemos una visión panorámica y bastante detallada de lo que ocurre en la parte sur de la costa sur durante la época de transición, en un territorio que llega hasta más arriba de los 3800 m.s.n.m y hasta poco antes del valle de Acarí. Más allá de los intercambios y negociaciones entre las élites que se perciben en la Península de Paracas, zona fronteriza entre la parte sur y norte de la Costa Sur, en el territorio estudiado en estos cuatro últimos artículos, podemos imaginar la vida cotidiana de la gente común, sin cambios importantes en lo «doméstico», pero afectada de una u otra manera por un período convulsionado, que está marcado por movimientos poblacionales del Norte hacia el Sur, con la llegada de elementos Topará, y de Este a Oeste, con la migración de pobladores serranos hacia la costa. En este contexto surgen nuevas maneras de hacer las cosas que implican la aparición de nuevas actividades en las cadenas productivas, llegan nuevas ideas que deben ser plasmadas de maneras novedosas como la producción de geoglifos, surge la necesidad de hacer ritos funerarios diferentes. En suma, se trata de una etapa de intensos cambios, que es mucho más que el final de una cultura y el inicio de otra. Una etapa en la que lo Topará juega un papel esencial según lo reportado por todos los artículos que conforman este volumen.

En este contexto, resulta crucial conocer lo que ocurre en los valles norteños, Cañete y Chincha, durante el período que nos ocupa. En el artículo que cierra el volumen, Isla hace un recuento detallado de los estudios pioneros realizados en esta zona por Wallace y otros, y presenta los resultados de sus excavaciones realizadas en el sitio El Mono, en Chincha. Este sitio, si bien es pequeño, presenta todas las características de un sitio de carácter ceremonial y brinda importante información respecto a procesos económicos y sociales que ocurren durante la fase Pinta, a finales de Paracas, justo antes de la transición. Sus hallazgos son muy similares a los recientemente reportados por Canziani, Stanish y Tantaleán para otros sitios del valle y contribuyen a la comprensión de los orígenes del desarrollo de lo que llamamos Topará y que afecta tan profundamente los valles sureños de la costa sur al final del último milenio a.C. 


\section{REFERENCIAS}

Althusser, L., É. Baribar, R. Establet, P. Macherey y J. Rancière

2016 Reading Capital [traducción de B. Brewster y D. Fernback], Verso Books.

[1965]

Bachir Bacha, A.

2007 Dinámica y desarrollo de un centro ceremonial andino, El caso de Cahuachi, Arqueología y Sociedad 18, 69-94.

2017 El edificio de los frisos de Ánimas Altas. Ser Paracas en el valle bajo de Ica, Boletín de Arqueología PUCP 22, 191-225. https://doi.org/10.18800/boletindearqueologiapucp.201701.008

Bachir Bacha, A. y O. D. Llanos

2013 ¿Hacia un urbanismo paracas en Ánimas Altas/Ánimas Bajas (valle de Ica)?, Boletín de Arqueología PUCP $17,169-204$.

Barthes, R.

1964 Éléments de sémiologie, en: Recherches sémiologiques, Communications 4(1), 91-135. https://doi. org/10.3406/comm.1964.1029

Bennett, W. C. (comp.)

1948 A reappraisal of Peruvian Archaeology, Society for American Archaeology/Institute of Andean Research, Menasha.

Berkhout, F., A. Smith y A.Stirling

2003 Socio-technological regimes and transition contexts, SPRU Electronic Working papers series 106. http:// www.dl.icdst.org/pdfs/files/5c5ac2ada424d164974fcb577de79000.pdf, consultado el 28-1-2017.

Bourdieu, P.

1977 Outline of a theory of practice [traducción de R. Nice], Cambridge Studies in Social and Cultural Anthropology (Book 16), Cambridge. https://doi.org/10.1017/CBO9780511812507

Braudel, F.

1993 A history of civilizations, Penguin Books, New York.

Canziani, J.

2009 Ciudad y territorio en los Andes: Contribuciones a la historia del urbanismo prehispánico, Fondo Editorial PUCP, Lima.

2013 Arquitectura, urbanismo y transformaciones territoriales del período paracas en el valle de Chincha, Boletin de Arqueologia PUCP 17, 9-29.

DeLeonardis, L.

1997 Paracas settlement in Callango, lower Ica Valley, Ist Millenium B.C., Peru, tesis de doctorado, Department of Anthropology, School of Art and Sciences, The Catholic University of America, Washington, D.C.

DeLeonardis, L. y M. D. Glascock

2013 From Quesqa to Callango: A Paracas obsidian assemblage from the Lower Ica Valley, Perú, Nawpa Pacha 33(2), 163-191. https://doi.org/10.1179/0077629713Z.0000000008

Domenici, D.

1994 La Transizione Paracas - Nasca. Nuovi deti su Cahuachi e i centri minori della valle di Nasca. Tesi di laurea in Storia r Civilita’dell'America Precolombiana, Università degli Studi di Bologna

Freeman, C.

1992 A green techno-economic paradigm for the world economy, en: C. Freeman (ed.), The Economics of Hope: Essays on Technical Change, Economic Growth, and the Environment, 190-211, Pinter Publishers, London. https://doi.org/10.3406/reco.1991.409276

García, R.

2013 Geoglifos Paracas de la Costa Sur: Cerro Lechuza y Cerro Pico, Boletín de Arqueología PUCP 17, 151-168. 
García, R. y J. Pinilla

1995 Aproximación a una secuencia de fases con cerámica temprana de la región de Paracas, en: A. Zighelboim y C. Barnes (eds.), Current Research in Andean Antiquity. Journal of the Steward Anthropological Society 23 $(1,2), 43-82$, Urbana.

Geels, F. W.

2010 Ontologies, socio-technical transitions (to sustainability), and the multi-level perspective, Research Policy 39, 495-510.

Gramsci, A.

1975 [1932] Letters from Prison, Antonio Gramsci, en: L Lawner (ed.), Harper Colophon, New York.

Isla, J., M. Reindel y J. C. de la Torre

2003 Jauranga: un sitio Paracas en el valle de Palpa, costa sur del Perú, Beiträge zur Allgemeinen und Vergleichenden Archäologie 23, 227-274.

Isla, J. y M. Reindel

2007 Los paracas del sur: una nueva perspectiva desde los valles de Palpa, en: Hilos del Pasado, El aporte francés al legado Paracas, 79-91, Instituto Nacional de Cultura, Lima.

Isla Cuadrado, J.

2009 From hunters to regional lords: Funerary practices in Palpa, Peru, en: M. Reindel y G. Wagner (eds.), New technologies for archaeology: Multidisciplinary investigations in Palpa and Nasca, Perú 119-139, Natural Science in Archaeology, Springer-Verlag, Berlin/Heidelberg. https://doi.org/10.1007/978-3540-87438-6_8

Johnson, G. A.

1978 Information and the development of decision-making organizations, en: C. L. Redman et al. (eds.), Social Archaeology: Beyond subsistence and dating, 87-112, Academic Press, New York.

1982 Organizational structure and scalar stress, en: C. Renfrew, M. Rowlands y B. Segraves (eds.), Theory and explanation in Archaeology: The Southampton Conference, 389-421, Academic Press, New York.

Marx, K.

1990 Capital: A critique of political economy, vol.1, Penguin Classics.

[1867]

Massey, S.

1986 Sociopolitical change in the upper Ica Valley, B.C. 400 to 400 A.D.: Regional states on the south coast of Peru, tesis de doctorado, Department of Archaeology, University of California, Los Angeles, University Microfilms, Ann Arbor.

1991 Social and political leadership in the lower Ica Valley: Ocucaje phases 8 and 9, en: A. Paul (ed.), Paracas Art and Architecture: Object and Context in South Coastal Peru, 315-348, University of Iowa Press, Iowa City.

\section{Menzel, D., J.H. Rowe y L.E. Dawson}

1964 The Paracas pottery of Ica; A study in style and time, Publications in American Archaeology and Ethnology 50, University of California, Berkeley.

Nigra, $B$.

2017 Huaca Soto and the evolution of Paracas communities in the Chincha Valley, Perú, tesis de doctorado, University of California, Los Angeles.

Orefici, G.

1998 Una expresión de arquitectura monumental Paracas-Nasca: El Templo del Escalonado de Cahuachi, Atti Convegno Internazionale: Archeologia, scienza y società dell'America, 191-201, CISRAP, Brescia.

2012 Cahuachi: Capital Teocrática Nasca, vols. I-II, Universidad San Martín de Porres, Lima.

Paul, A.

1991 Paracas: An Ancient Cultural Tradition on the South Coast of Peru, en: A. Paul (ed.), Paracas: Art and architecture. Object and context in south coastal Peru, University of Iowa Press, Iowa City. 
Pérez, K., A. Fernández, H. Tantaleán y C. Stanish

2015 El estilo cerámico Carmen y su presencia en el valle medio de Chincha, costa sur del Perú, Bulletin de l'Institut Français d'Études Andines 44 (2), 181-204. https://doi.org/10.4000/bifea.7555

Peters, A. H.

1997 Paracas, Topará and Early Nasca: Ethnicity and Society on the South Central Andean Coast, tesis de doctorado, Cornell University, University Microfilms, Ann Arbor.

2013 Topará en Pisco: Patrón de asentamiento y paisaje, Boletín de Arqueología PUCP 17, 77-101.

Proulx, D.

1968 Local differences and time differences in Nasca pottery, University of California Publications in Anthropology 5, University of California Press, Berkeley/Los Angeles.

Reindel, $\mathrm{M}$.

2009 Life at the edge of the desert - archaeological reconstruction of the settlement history in the valleys of Palpa, Perú, en: M. Reindel y G. Wagner (eds.), New technologies for archaeology, multidisciplinary investigations in Palpa and Nasca, Perú, 119-13, Springer-Verlag, Berlin/Heidelberg. https://doi.org/ 10.1007/978-3-540-87438-6

2014 Transecta Andina: Estudios de interregionalidad y verticalidad en los Andes del sur del Perú, en Las conexiones temporales, regionales y transatlánticas de los Andes y la Amazonía: personas y objetos como actores de una historia entrelazada, I. Kummels y K. Noack (coords.), Nuevo Mundo/Mundos Nuevos: Debates. https://doi.org/10.4000/nuevomundo.67450

Reindel, M. y J. Isla

2017 Nuevo patrón arqueológico paracas en Lucanas, sierra sur del Perú, Boletín de Arqueología PUCP 22, 227-254. https://doi.org/10.18800/boletindearqueologiapucp.201701.009

Rip, A. y R. Kemp

1998 Technological change, en: S. Rayner y E. Malone (eds.), Human Choices and climate change, vol. 2, 327-399, Battelle, Columbus.

Rowe, J. H.

1960 Nuevos datos relativos a la cronología del estilo Nasca, en: Antiguo Perú. Espacio y tiempo: Trabajos presentados a la semana de Arqueología Peruana (9-14 de noviembre 1959), 29-45, Editorial Juan Mejía Baca, Lima.

Rubini, A. y L. E. Dawson

s.f. 1957-1960 Notes on burials excavated at Ocucaje and photographs of the Rubini collection, Lawrence E. Dawson papers, BANC MSS 95/21 c, The Bancroft Library, University of California, Berkeley.

Schreiber, K. y J. Lancho

2003 Irrigation and society in the Peruvian desert: The puquios of Nasca, Lexington Books, Boston.

Silverman, $\mathrm{H}$.

1997 The first field season of excavations at the Alto del Molino Site, Pisco Valley, Peru, Journal of Field Archaeology 24, 441-457. https://doi.org/10.1179/jfa.1997.24.4.441

Silverman, H. y D. Proulx

2002 The Nasca, peoples of America; Blackwell Publ., Malden/Oxford. https://doi.org/10.1002/9780470693384

Strong, W. D.

1957 Paracas, Nazca, and Tiabuanacoid relationships in south coastal Peru, Memoirs of the Society for American Archaeology 13, Salt Lake City.

Tantaleán, $\mathrm{H}$.

2016 Paisajes rituales y políticos Paracas en el valle de Chincha, costa sur del Perú, Latin American Antiquity 27(4), 479-496. https://doi.org/10.7183/1045-6635.27.4.479

Tantaleán, H., C. Stanish, K. Pérez y A. Rodriguez

2017 Las ocupaciones paracas y topará en Cerro del gentil, valle de Chincha, Boletín de Arqueología PUCP 22, 61-89. https://doi.org/10.18800/boletindearqueologiapucp.201701.003 
Tello, J. C.

1929 Antiguo Perú. Primera época, Comisión Organizadora del Segundo Congreso Sudamericano de Turismo, Lima.

1930 Andean civilization: some problems of Peruvian Archaeology, Proceedings of the XXIII International Congress of Americanists (September 17-22, 1928), 259-290, New York.

1959 Paracas. Primera Parte, Publicación del Proyecto 8b del Programa 1941-1942 del Institute of Andean Research, Empresa Gráfica T. Scheuch S.A., Lima.

2009 Paracas Cavernas. Cuaderno del Archivo Tello 7, Museo de Arqueología y Antropología, Universidad Nacional Mayor de San Marcos, Lima.

2012 Paracas Wari Kayan, Cuaderno del Archivo Tello 9, Museo de Arqueología y Antropología, Universidad Nacional Mayor de San Marcos, Lima.

Tello, J. C. y T. Mejía Xesspe

1979 Paracas, segunda parte: Cavernas y Necrópolis, Universidad Nacional Mayor de San Marcos/Institute of Andean Research, Lima.

Tomasto-Cagigao, E., M. Reindel y J. Isla

2015 Paracas funerary practices in Palpa, South coast of Peru, en: P. Eeckhout y L.S. Owens (eds.), Funerary practices and models in the ancient Andes: The return of the living dead, Cambridge University Press, Cambridge.

Uhle, $M$.

1914 The Nazca pottery of ancient Peru, Proceedings of the Davenport Academy of Sciences 13, 1-16.

Unkel, I. y B. Kromer

2009 The Clock in the Corn Cob: On the development of a Chronology of the Paracas and Nasca Period based on Radiocarbon Dating, en: M. Reindel and G, Wagner (eds.), New Technologies for Archaeology, pp. 231-244. (Series) Natural Scence in Archaeology, Springer-Verlag, Berlin/Heidelberg. https://doi. org/10.1007/978-3-540-87438-6_14

\section{Van Gijseghem, $\mathrm{H}$.}

2006 A frontier perspective on Paracas Society and Nasca Ethnogenesis, Latin American Antiquity 17(4), 419-444. https://doi.org/10.2307/25063066

\section{Vaughn, K. y H. Van Gijseghem}

2007 A compositional perspective on the origins of the "Nasca Cult» at Cahuachi, Journal of Archaeological Science 34, 814-822. https://doi.org/10.1016/j.jas.2006.08.008

Wallace, D.

1971- Sitios Arqueológicos del Perú (Segunda entrega): Valles de Chincha y Pisco, Sumario de la secuencia

1972 Cultural de los valles de Chincha y Pisco [traducción de L. Watanabe Matsukura], Arqueológicas 13.

1985 Paracas in Chincha and Pisco: A reappraisal of the Ocucaje Sequence, en: P. Kvietok y D. Sandweiss (eds.), Recent studies in Andean prehistory and protohistory. Papers from the Second Annual Northeast Conference on Andean Archaeology and Ethnohistory, 67-94, Latin American Studies Program, Cornell University, Ithaca.

\section{Weber, $\mathrm{M}$.}

1946 The social psychology of the world religions, en: H.H. Gerth y C. Wright Mills (eds.), [1922-1923] From Max Weber, 267-301, Oxford University Press, New York. 